\title{
The Cost-Effectiveness of Surgical Treatment of Medial Unicompartmental Knee Osteoarthritis in Younger Patients
}

\author{
A Computer Model-Based Evaluation
}

Joseph F. Konopka, MD, MSc, Andreas H. Gomoll, MD, Thomas S. Thornhill, MD, Jeffrey N. Katz, MD, MSc, and Elena Losina, PhD Investigation performed at the Department of Orthopedic Surgery, Brigham and Women's Hospital, Boston, Massachusetts

\begin{abstract}
Background: Surgical options for the management of medial compartment osteoarthritis of the varus knee include high tibial osteotomy, unicompartmental knee arthroplasty, and total knee arthroplasty. We sought to determine the costeffectiveness of high tibial osteotomy and unicompartmental knee arthroplasty as alternatives to total knee arthroplasty for patients fifty to sixty years of age.
\end{abstract}

Methods: We built a probabilistic state-transition computer model with health states defined by pain, postoperative complications, and subsequent surgical procedures. We estimated transition probabilities from published literature. Costs were determined from Medicare reimbursement schedules. Health outcomes were measured in quality-adjusted life-years (QALYs). We conducted analyses over patients' lifetimes from the societal perspective, with health and cost outcomes discounted by $3 \%$ annually. We used probabilistic sensitivity analyses to account for uncertainty in data inputs.

Results: The estimated discounted QALYs were 14.62, 14.63, and 14.64 for high tibial osteotomy, unicompartmental knee arthroplasty, and total knee arthroplasty, respectively. Discounted total direct medical costs were $\$ 20,436$ for high tibial osteotomy, $\$ 24,637$ for unicompartmental knee arthroplasty, and $\$ 24,761$ for total knee arthroplasty (in 2012 U.S. dollars). The incremental cost-effectiveness ratio (ICER) was $\$ 231,900$ per QALY for total knee arthroplasty and $\$ 420,100$ per QALY for unicompartmental knee arthroplasty. Probabilistic sensitivity analyses showed that, at a willingnessto-pay (WTP) threshold of $\$ 50,000$ per QALY, high tibial osteotomy was cost-effective $57 \%$ of the time; total knee arthroplasty, 24\%; and unicompartmental knee arthroplasty, 19\%. At a WTP threshold of $\$ 100,000$ per QALY, high tibial osteotomy was cost-effective $43 \%$ of time; total knee arthroplasty, $31 \%$; and unicompartmental knee arthroplasty, $26 \%$.

Conclusions: In fifty to sixty-year-old patients with medial unicompartmental knee osteoarthritis, high tibial osteotomy is an attractive option compared with unicompartmental knee arthroplasty and total knee arthroplasty. This finding supports greater utilization of high tibial osteotomy for these patients. The cost-effectiveness of high tibial osteotomy and of unicompartmental knee arthroplasty depend on rates of conversion to total knee arthroplasty and the clinical outcomes of the conversions.

Level of Evidence: Economic Level II. See Instructions for Authors for a complete description of levels of evidence.

Peer Review: This article was reviewed by the Editor-in-Chief and one Deputy Editor, and it underwent blinded review by two or more outside experts. It was also reviewed by an expert in methodology and statistics. The Deputy Editor reviewed each revision of the article, and it underwent a final review by the Editor-in-Chief prior to publication. Final corrections and clarifications occurred during one or more exchanges between the author(s) and copyeditors.

Disclosure: One or more of the authors received payments or services, either directly or indirectly (i.e., via his or her institution), from a third party in support of an aspect of this work. In addition, one or more of the authors, or his or her institution, has had a financial relationship, in the thirty-six months prior to submission of this work, with an entity in the biomedical arena that could be perceived to influence or have the potential to influence what is written in this work. Also, one or more of the authors has had another relationship, or has engaged in another activity, that could be perceived to influence or have the potential to influence what is written in this work. The complete Disclosures of Potential Conflicts of Interest submitted by authors are always provided with the online version of the article. 
The Journal of Bone \& Joint Surgery $\cdot$ JbjS. org VOlume 97-A $\cdot$ Number $10 \cdot$ May 20, 2015
Cost-Effectiveness of Surgical Treatment of Medial

Unicompartmental KneE OSTEOARTHRITIS
$\mathrm{T}$ here is no consensus as to the optimal surgical treatment for patients in their fifties with end-stage medial unicompartmental osteoarthritis, varus deformity, and persistent symptoms despite nonoperative therapy. Surgical options include valgus-producing high tibial osteotomy (HTO), unicompartmental knee arthroplasty (UKA), and total knee arthroplasty (TKA). Each option has advantages and disadvantages .

Periarticular HTO is an accepted treatment in young, active patients with medial compartment osteoarthritis. It provides reliable pain relief by altering the mechanical axis of the lower limb to unload the arthritic compartment. Compared with knee arthroplasty, HTO may provide more natural kinematic function because the joint is not opened and structures about the knee are retained ${ }^{2}$. However, long-term HTO survival has ranged from $30 \%$ to $90 \%{ }^{3}$, and the function of a TKA performed following an HTO is not well established ${ }^{4-6}$.

UKA was traditionally indicated for patients older than sixty years of age ${ }^{7}$. With improved implant design and surgical technique, UKA increasingly has been used in younger patients. Compared with TKA, a well-functioning UKA may result in improved range of motion, better gait pattern, shorter recovery period, and lower rate of deep venous thrombosis'. However, implant survivorship has varied, from $70 \%$ to $96.5 \%$ at five to ten years of follow-up, and higher rates of revision relative to TKA have been observed in multiple joint registries ${ }^{10-18}$.

In recent decades, younger patients with end-stage osteoarthritis increasingly have been offered TKA, although these patients may expose the implant to greater mechanical stress ${ }^{19}$. While survival rates of TKA may exceed those of UKA in younger patients $^{10}$, revision TKA may be more technically complex and expensive than primary TKA or revision $\mathrm{UKA}^{20}$.

Two recent studies compared the cost-effectiveness of UKA and TKA in older patients, finding UKA to be cost-effective if survivorship exceeded twelve years ${ }^{21}$ or failure rates were $<4 \%$ annually ${ }^{22}$. Other recent studies were limited by excluding quality-of-life analysis ${ }^{23}$ or by use of only short-term data ${ }^{24}$. Brown et al. ${ }^{25}$ compared the cost-effectiveness of HTO, UKA, and TKA in forty-year-old patients, finding that UKA produced the highest health benefit at an ICER (incremental cost-effectiveness ratio) of $\$ 1048$ per QALY (quality-adjusted life-year) (in 2008 U.S. dollars). However, subsequent studies suggest that the failure rate of UKA used in this model was too

\begin{tabular}{|c|c|c|c|c|c|}
\hline & HTO & UKA & Primary TKA & Aseptic Revision TKA & Septic Revision TKA \\
\hline \multicolumn{6}{|l|}{$\begin{array}{l}\text { Transition } \\
\text { probabilities }\end{array}$} \\
\hline $\begin{array}{l}\text { Early implant } \\
\text { failure } †\end{array}$ & $3.36 \%^{58,59,99-106}$ & $2.63 \%^{11-13,15,16,18,26}$ & $0.57 \%^{10,15,16,62}$ & $3.53 \%^{20,53}$ & $3.53 \%^{20,52}$ \\
\hline $\begin{array}{l}\text { Late implant } \\
\text { failure }\end{array}$ & $2.32 \% 3,10,40$ & $2.32 \%^{11-13,15,16,18,26}$ & $1.21 \%^{6,15-17,23,26,29,34,39,60,62}$ & $3.53 \%^{20,53}$ & $3.53 \%^{20,52}$ \\
\hline Revision failure & $1.6 \%^{6}$ & $1.6 \%^{6,20,53,107}$ & $3.53 \%^{20,53}$ & $3.53 \%^{20,52}$ & $3.53 \%^{20,53}$ \\
\hline \multicolumn{6}{|l|}{ Quality of life (QALYS) } \\
\hline Optimal implant§ & $0.835^{3,40,108}$ & $0.835^{17,24,27,34,69-73}$ & $0.835^{21,22,25,61-68,74,109}$ & $0.772^{21,22,25,64,67,109}$ & $0.756^{22,110}$ \\
\hline Optimal revision\# & $0.804^{4-6,85,86,88,90,111}$ & $0.804^{6,13,75-78}$ & $0.772^{21,22,25,63,66,108}$ & $0.772^{21,22,25,64,67,109}$ & $0.756^{22,109}$ \\
\hline Aseptic failure & $0.69^{21,22,25,62,65,68,74}$ & $0.69^{21,22,25,62,65,68,74}$ & $0.69^{21,22,25,62,65,68,74}$ & $0.69^{21,22,25,62,65,68,74}$ & $0.69^{21,22,25,62,65,68,74}$ \\
\hline Septic failure & $0.5^{21,22,25}$ & $0.5^{21,22,25}$ & $0.5^{21,22,25}$ & $0.5^{21,22,25}$ & $0.5^{21,22,25}$ \\
\hline \multicolumn{6}{|l|}{ Costs (2012 USD) } \\
\hline Preop. work-up** & $\$ 236^{112-114}$ & $\$ 236^{112-114}$ & $\$ 236^{112-114}$ & $\$ 236^{112-114}$ & $\$ 641^{112-114}$ \\
\hline Anesthesia fee & $\$ 323^{115}$ & $\$ 323^{115}$ & $\$ 387^{115}$ & $\$ 482^{115}$ & $\$ 805^{115}$ \\
\hline Surgeon fee & $\$ 962^{112}$ & $\$ 1109^{112}$ & $\$ 1544^{112}$ & $\$ 1768^{112}$ & $\$ 3302^{112}$ \\
\hline $\begin{array}{l}\text { Surgery and acute } \\
\text { care }\end{array}$ & $\$ 6135^{92}$ & $\$ 9831^{92}$ & $\$ 9831^{92}$ & $\$ 12,784^{92}$ & $\$ 17,425^{92}$ \\
\hline $\begin{array}{l}\text { Rehabilitation or } \\
\text { home therapy } \uparrow \dagger\end{array}$ & $\$ 2099^{92,116}$ & $\$ 1618^{92,116}$ & $\$ 3383^{92,116}$ & $\$ 5376^{92,116}$ & $\$ 10,593^{92,116}$ \\
\hline $\begin{array}{l}\text { Additional postop. } \\
\text { costs } \neq \uparrow\end{array}$ & $\$ 252^{112,113,116}$ & $\$ 252^{112,113,116}$ & $\$ 252^{112,113,116}$ & $\$ 252^{112,113,116}$ & $\$ 364^{112,113,116}$ \\
\hline $\begin{array}{l}\text { Annual postop. } \\
\text { evaluations§§ }\end{array}$ & - & $\$ 93^{112,113,117}$ & $\$ 93^{86,112,118}$ & $\$ 93^{86,112,118}$ & $\$ 93^{86,112,118}$ \\
\hline Additional costs\#\# & - & - & - & - & $\$ 4635^{112-114}$ \\
\hline
\end{tabular}

$* \mathrm{HTO}=$ high tibial osteotomy, UKA = unicompartmental knee arthroplasty, and TKA = total knee arthroplasty. †The probability of failure of the implant within one year of the procedure. $\neq$ The annual probability of implant failure after one year postoperatively. §The annual QALYs gained from an optimal implant. \#The annual QALYs gained from an optimal revision of the implant. **Includes physician visit, preoperative imaging, and preoperative laboratory tests. $\dagger \uparrow$ Average expense of postoperative care based on the patient's expected disposition to a rehabilitation facility or home, with or without home health care or outpatient physical therapy. $\neq \neq$ Additional postoperative medications and additional physician visits and imaging outside of the ninety-day global reimbursement window. $\S \S A v e r a g e$ annualized costs of physician visits and imaging after the first postoperative year. \#\#Additional expenses associated with a septic knee prosthetic revision, including infectious disease consultation and follow-up visits, central venous access, intravenous antibiotics, laboratory monitoring while on intravenous antibiotics, and knee aspirations. 
The Journal of Bone \& Joint Surgery - Jbjs. org VOlume 97-A - Number $10 \cdot$ May 20, 2015
Cost-Effectiveness of Surgical Treatment of Medial

Unicompartmental KneE Osteoarthritis low $^{8,10-15,17,18,23,26-39}$ and that the failure rate of HTO was too $\operatorname{high}^{3,6,40}$.

Our goal was to examine the cost-effectiveness of HTO and UKA as alternatives to TKA for the treatment of medial compartment osteoarthritis with varus deformity in patients fifty to sixty years old - a decade during which indications for these procedures overlap.

\section{Materials and Methods Analytic Overview}

W ${ }^{\text {e built a state-transition computer model of alternative surgical treatments }}$ for patients who failed conservative therapy for medial unicompartmental osteoarthritis with varus deformity. The model was created using TreeAge Pro software (TreeAge Software, Williamstown, Massachusetts) ${ }^{41}$. Outcomes included QALYs, costs, and ICERs. A QALY is a measurement of quality of life defined on a 0 to 1 scale; a year of perfect health is worth 1 QALY, and a year of less than perfect health is worth $<1$ QALY $^{42}$. The value of a QALY reflects patient morbidity and lost productivity ${ }^{43}$. Both QALYs and costs were discounted by $3 \%$ annually. ICERs were calculated as the difference in costs divided by the difference in QALYs between two treatments. ICERs quantify the additional cost-per-QALY gained in switching from one medical intervention to another ${ }^{44}$, thereby allowing comparison of the value provided by different health interventions. We evaluated three surgical strategies: HTO, UKA, and TKA. Our analysis conformed to the guidelines of the U.S. Panel on Cost-Effectiveness in Health and Medicine ${ }^{43}$.

Willingness-to-pay (WTP) per QALY is the limit at which society is no longer willing to spend resources to gain additional QALYs ${ }^{45}$. We considered three commonly used WTP thresholds: $\$ 50,000$ per QALY, $\$ 100,000$ per QALY, and $\$ 150,000$ per QALY $^{46}$. A treatment was considered cost-effective if its ICER was below the WTP threshold and was "dominated" if it was less effective but more costly than an alternative. If a treatment's ICER was greater than that of more effective alternatives, we refer to it as having "extended dominance."47

Additionally, we performed value-of-information analyses. These analyses determine the benefit from obtaining additional information to eliminate uncertainty and better inform a decision. We estimated the expected value of partial perfect information (EVPPI) by hypothetically eliminating the uncertainty in several model parameters. This allowed us to identify targets for future research ${ }^{48}$.
We estimated the benefit to society by multiplying the benefit per patient by the number of patients in the fifty-to-sixty age range who would face treatment decisions annually ${ }^{49-52}$.

\section{Model Structure}

Figure 1 illustrates the Markov model structure. Patients entered the simulation at the time of surgery. The model independently accounted for perioperative medical and surgical complications. Medical complications included myocardial infarction, deep venous thrombosis, pulmonary embolism, and death, and surgical complications included aseptic failure, nonunion, or deep infection. Surgical results were stratified as "optimal" or "suboptimal," with those in the "optimal" state having greater quality of life. Patients in a "suboptimal" state were those with pain, aseptic component loosening, or disease progression. Each year, patients could transition from "optimal" to "suboptimal" or remain in the same health state as the previous year. Patients in a "suboptimal" state were at risk for a revision procedure, which was assumed to be a TKA for those whose index procedure was HTO or UKA ${ }^{53}$. Patients with a knee implant failure due to sepsis undergo a twostage revision procedure ${ }^{54}$. After revision, patients were similarly stratified to an "optimal" or "suboptimal" post-revision state, which was associated with lower quality of life than the corresponding primary procedure. Patients within a "suboptimal" post-revision state were at risk for repeat revision surgery. Patient age at the time of the initial procedure ranged from fifty to sixty years, with an average of fifty-five years. We conducted the analysis over patients' lifetimes. Table I summarizes input parameters, which were stratified by transition probabilities, quality of life, and costs.

\section{Transition Probabilities}

The probability of perioperative medical complications was obtained from literature that investigated complications among age-stratified TKA patients ${ }^{55}$ and was assumed to be similar for UKA, HTO, and revision procedures ${ }^{40,56,57}$. After the initial procedure, patients had a $1.1 \%$ chance of medical complications. For subsequent procedures, patients experienced a higher probability of medical complications on the basis of their age. Annual other-cause mortality was determined from United States Life Tables ${ }^{49}$.

The probability of HTO failure after one year was assumed to be the same as that of UKA failure on the basis of a Swedish registry study and two recent meta-analyses ${ }^{3,10,40}$. We estimated a $3.36 \%$ rate of deep infection or nonunion

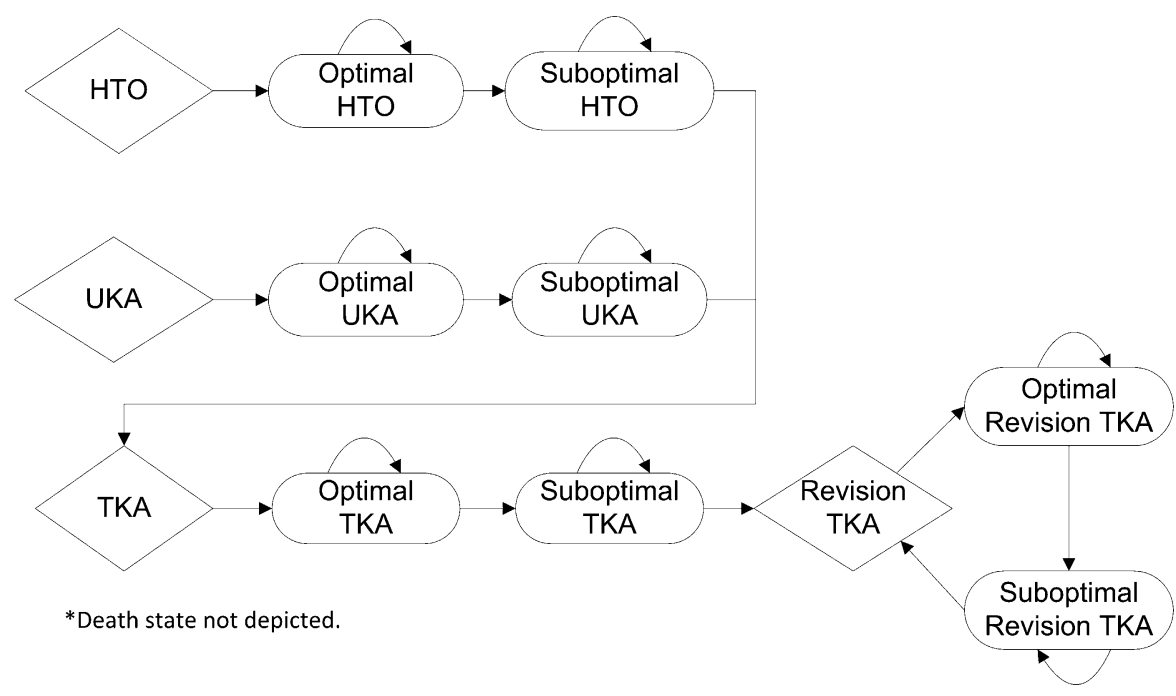

Fig. 1

The structure of the Markov model for high tibial osteotomy (HTO), unicompartmental knee arthroplasty (UKA), and total knee arthroplasty (TKA). Diamonds represent transition states during which a surgical intervention occurs. Ovals represent transition states during which no surgical intervention occurs. Straight arrows indicate a transition to a different transition state, and curved arrows indicate staying in the same transition state. Two transition states are not depicted: permanently living with a suboptimal prosthesis and the absorbing death state. 


\begin{tabular}{|c|c|c|c|c|c|c|c|}
\hline Intervention & Cost & QALY & $\begin{array}{l}\text { ICER (cost } \\
\text { per QALY) }\end{array}$ & $\begin{array}{l}\text { Conversion to TKA } \\
\text { within Ten Years } \\
\text { (Std. Dev.) }\end{array}$ & $\begin{array}{l}\text { Conversion to TKA } \\
\text { within Lifetime } \\
\text { (Std. Dev.) }\end{array}$ & $\begin{array}{c}\text { Revision TKA } \\
\text { within Ten Years } \\
\text { (Std. Dev.) }\end{array}$ & $\begin{array}{l}\text { Revision TKA } \\
\text { within Lifetime } \\
\text { (Std. Dev.) }\end{array}$ \\
\hline HTO & $\$ 20,436$ & 14.62 & - & $16 \%(1.2 \%)$ & $40 \%$ (1.5\%) & $0.9 \%(0.4 \%)$ & $10 \%(0.9 \%)$ \\
\hline UKA & $\$ 24,637$ & 14.63 & $\begin{array}{l}\text { Extended } \\
\text { dominance } \dagger\end{array}$ & $18 \%(1.2 \%)$ & $42 \%$ (1.5\%) & $1.4 \%(0.4 \%)$ & $11 \%(1.0 \%)$ \\
\hline TKA & $\$ 24,761$ & 14.64 & $\$ 231,900$ & - & - & $10.7 \%(1.0 \%)$ & $37 \%(1.4 \%)$ \\
\hline
\end{tabular}

*QALY $=$ quality-adjusted life-year, and ICER $=$ incremental cost-effectiveness ratio. $\dagger$ In extended dominance, an intervention has an ICER that is greater than that of a more effective alternative; ICER $=\$ 420,100$.

within one year following HTO from recent reviews of HTO complications ${ }^{58,59}$. The probability of UKA failure was determined from a literature search of studies from 2004 to 2013. Of twenty-seven studies identified, nine studies analyzed revision rates in a cohort of UKA patients younger than sixty-one years old ${ }^{11-18,26}$. From these studies, we derived a UKA implant failure rate of $2.63 \%$ during the first postoperative year and $2.32 \%$ annually thereafter.

We estimated the probability of TKA failure at $0.57 \%$ within the first year and $1.21 \%$ in subsequent years by summarizing published literature regarding TKA failure rates for the appropriate patient age range $\mathrm{e}^{6,10,15-17,23,29,34,39,60}$. We derived a $3.53 \%$ annual failure rate of a revision TKA requiring a repeat surgery as a weighted average of results reported in registry data ${ }^{20,53}$.

All patients with a prosthetic failure due to sepsis were treated with a twostage revision ${ }^{54}$. We assumed that $100 \%$ of patients who had an aseptic prosthetic failure within the first year would undergo revision surgery, whereas patients with an aseptic failure in subsequent years were assumed to undergo revision on the basis of their age at the time of failure, with fewer elderly patients electing to undergo a revision.

\section{Quality of Life}

Median reported QALYs for an optimal TKA among recent studies was $0.835^{21,22,25,61-68}$. Quality of life for an optimal primary HTO, UKA, and TKA was assumed to be similar on the basis of nine studies that compared UKA with TKA within the last decade and found similar clinical scores using a variety of validated instruments ${ }^{11,17,24,27,34,69-73}$ as well as on the basis of two recent metaanalyses comparing HTO and UKA ${ }^{3,40}$. Median reported QALYs after an optimal revision TKA was $0.772^{21,22,25,62,64,65,68,74}$. Data on the performance of $\mathrm{HTO}^{5-7,36,65-70}$ or UKA $\mathrm{UK}^{6,13,75-78}$ converted to TKA have been limited. Some studies have found that conversions of HTO and UKA to TKA have results similar to primary TKA, while other studies have found worse outcome scores relative to primary TKA. Therefore, we estimated the quality of life for conversion of both HTO and UKA to TKA to be midway between that of primary and revision TKA, or 0.804 QALYs. On the basis of published literature, we incorporated a $40 \%$ loss of QALYs during a twelve-week recovery after a TKA, HTO, or revision procedure, and a $30 \%$ loss of QALYs during recovery from a UKA ${ }^{21,25,67,79}$.

\section{Costs}

We included costs associated with primary HTO, UKA, and TKA procedures as well as conversion of HTO and UKA to TKA, TKA revision due to aseptic failure, two-stage revision due to septic failure, debridement for deep infection following an HTO, and revision due to nonunion following HTO. For each procedure, we used average Medicare reimbursement rates to estimate costs of physician visits, preoperative imaging, preoperative laboratory tests, anesthesia fees, surgeon fees, surgery-related technical needs, acute inpatient recovery, major medical complications, postoperative rehabilitation, and postoperative evaluations. Costs were varied by $30 \%$ above and below the base value in sensitivity analyses. All costs were expressed in 2012 U.S. dollars using the medical component of the Consumer Price
Index ${ }^{80}$. We estimated average total first-year costs of an uncomplicated HTO, UKA, and TKA at $\$ 10,006, \$ 13,369$, and $\$ 15,634$, respectively (see Appendix).

\section{Sensitivity Analyses}

We conducted sensitivity analyses to determine how data uncertainty affects the result. We utilized one-way and two-way deterministic sensitivity analyses to evaluate how the cost-effectiveness of treatment strategies changes as a result of variations in specific model parameters. Additionally, we conducted a probabilistic sensitivity analysis to determine the effect of joint uncertainty in multiple parameters by repeating a cost-effectiveness analysis 10,000 times. Each time, the model drew parameters from prespecified distributions that took uncertainty around point estimates into consideration. We used beta distributions for implant failure rates because the beta distribution is ideal for binomial data in which the number of failures in a given sample size is known ${ }^{81}$. We constructed a costeffectiveness acceptability curve, which demonstrates the probability that an intervention is cost-effective over a range of WTP thresholds ${ }^{82}$ (see Appendix).

\section{Source of Funding}

Research was supported by the National Institute of Arthritis and Musculoskeletal and Skin Diseases of the National Institutes of Health (NIH/NIAMS R01-AR064320, T32AR055885).

\section{Results}

Base Case

Table II presents the results of the base case analysis. Patients undergoing HTO and UKA had an estimated $16 \%$ and $18 \%$ chance, respectively, of undergoing conversion to TKA within ten years, and a $40 \%$ and $42 \%$ chance, respectively, of having a conversion to TKA within their lifetime. Patients undergoing HTO and UKA had a $10 \%$ and $11 \%$ chance, respectively, of requiring both conversion to TKA and eventual revision TKA within their lifetime. In contrast, primary TKA patients had a 37\% chance of undergoing a revision TKA in their lifetime.

We estimated QALYS of 14.62, 14.63, and 14.64 for HTO, UKA, and TKA, respectively. Lifetime direct medical costs were $\$ 20,436$ for HTO, \$24,637 for UKA, and \$24,761 for TKA. TKA demonstrated an ICER of $\$ 231,900$ per QALY gained, which was higher than our highest WTP threshold of \$150,000. UKA was less effective and less costly than TKA but had an even greater ICER: $\$ 420,100$ per QALY. It was therefore determined to have shown extended dominance.

We estimated that HTO could save approximately $\$ 4263$, on average, compared with UKA or TKA, when considering 
The Journal of Bone \& Joint Surgery $\cdot$ JBjs.org VOlume $97-\mathrm{A} \cdot$ Number $10 \cdot$ MAY 20, 2015
Cost-Effectiveness of Surgical Treatment of Medial

Unicompartmental KneE Osteoarthritis
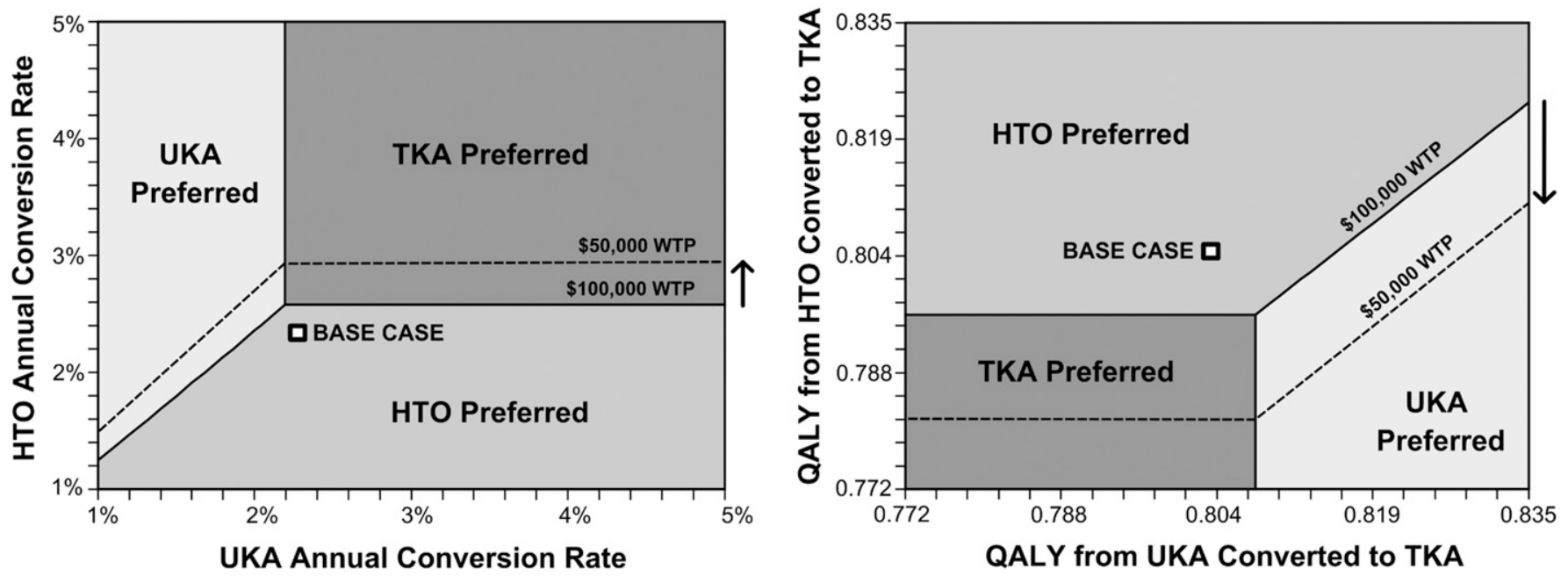

Fig. 2

Two-way sensitivity analyses of the rates of conversion to total knee arthroplasty (TKA) for unicompartmental knee arthroplasty (UKA) versus high tibial osteotomy (HTO) (left panel) and the utility of conversion for UKA versus HTO (right panel). Cost-effectiveness was compared when the annual rates of conversion and annual utility derived from conversion were allowed to vary. The willingness-to-pay (WTP) threshold of $\$ 100,000$ per quality-adjusted life-year (QALY) is depicted by a solid line, and the WTP threshold of $\$ 50,000$ per QALY is depicted by the dashed line. The base case is indicated by the white square.

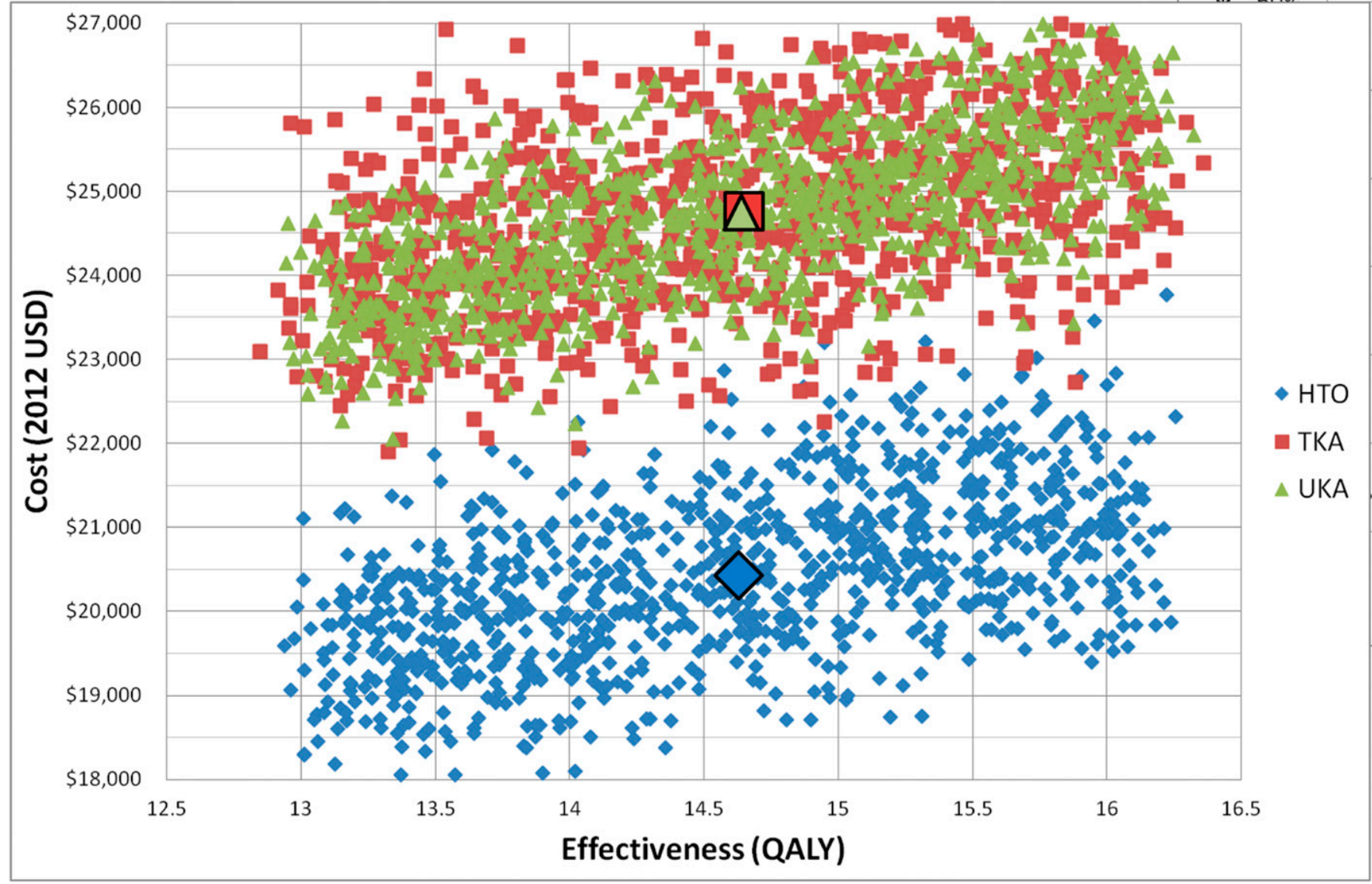

Fig. 3

Cost-effectiveness scatter plot of a Monte Carlo model of 10,000 theoretical patients, fifty to sixty years of age, undergoing each surgical strategy. Each outcome is represented by a dot colored to correspond with the primary surgery. The mean values for high tibial osteotomy (HTO), total knee arthroplasty (TKA), and unicompartmental knee arthroplasty (UKA) are represented by the large diamond, square, and triangle, respectively. 


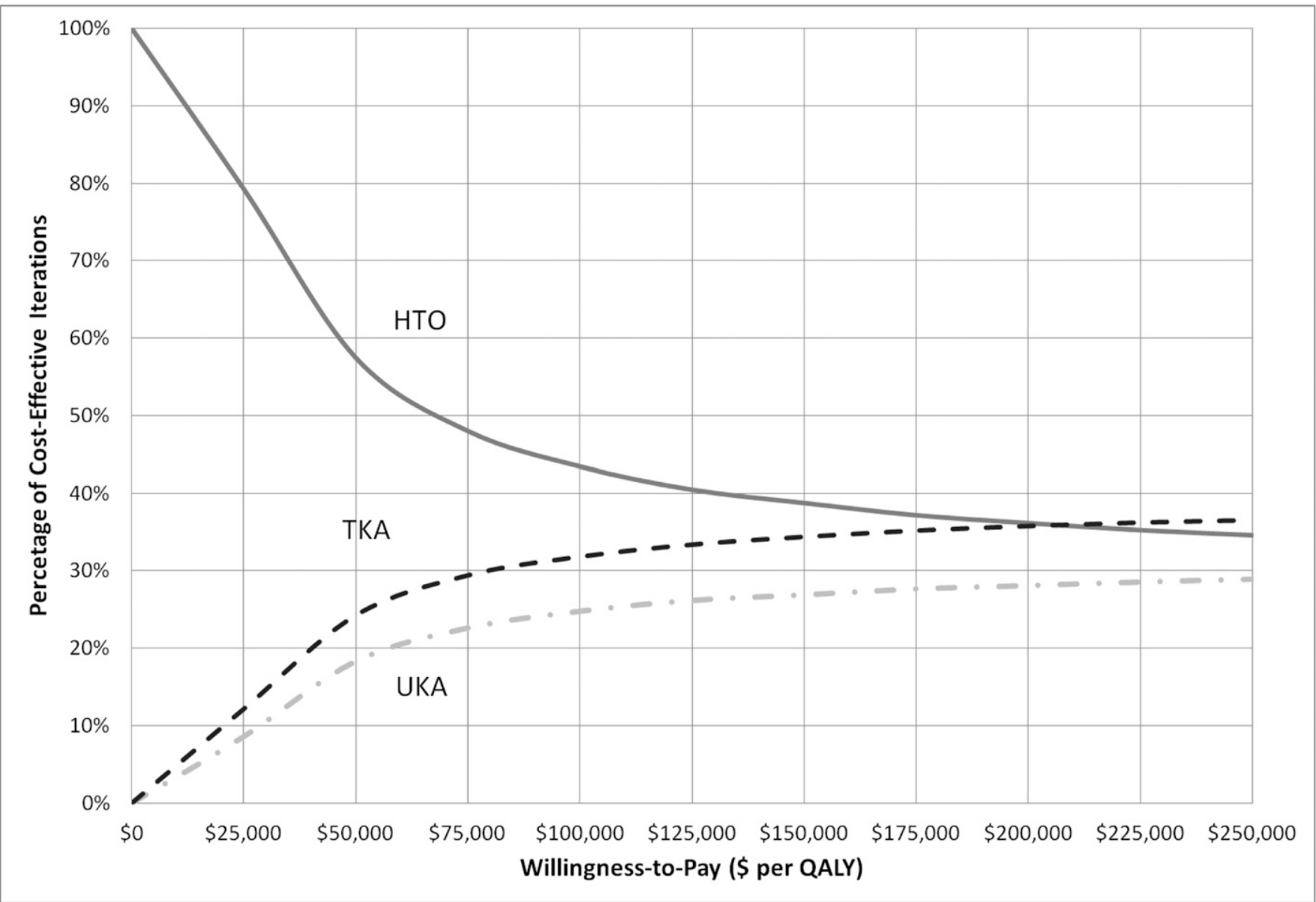

Fig. 4

Cost-effectiveness acceptability curve. This figure demonstrates the probability of each surgical option being the cost-effective strategy at a given willingness-to-pay threshold, utilizing a Monte Carlo simulation of 10,000 patients. HTO = high tibial osteotomy, TKA = total knee arthroplasty, and UKA = unicompartmental knee arthroplasty.

complications, conversions, and revision throughout the patient's lifetime.

\section{Sensitivity Analyses}

\section{Conversion to TKA}

Cost-effectiveness results were sensitive to annual conversion rates of both HTO and UKA to TKA (Fig. 2, left panel). At the WTP threshold of $\$ 100,000$ per QALY, if the HTO annual conversion rate increased to $2.6 \%$ from a baseline value of $2.3 \%$ annually, then TKA became the cost-effective strategy. Similarly, if the UKA annual conversion rate fell to $<2.0 \%$, then UKA became the costeffective strategy. However, at the lower WTP threshold of $\$ 50,000$ per QALY, the findings were more robust: TKA became the costeffective strategy only if the HTO annual conversion rate increased to $2.9 \%$, from a baseline value of $2.3 \%$ annually.

\section{Quality of Life}

The results were also sensitive to quality of life for the conversion of both HTO and UKA to TKA (Fig. 2, right panel). If the QALY associated with a satisfactory conversion of HTO to TKA was $14 \%$ less than the baseline value of 0.804 , TKA became a cost- effective strategy. If the QALY from a satisfactory conversion of UKA to TKA was $19 \%$ greater than the baseline of 0.804 , then UKA became a cost-effective strategy. Similarly, the findings were more robust at a lower WTP of $\$ 50,000$ per QALY: TKA became the cost-effective strategy only if the QALY from a satisfactory conversion of HTO to TKA was $36 \%$ lower than the baseline value of 0.804

Several factors had no bearing on cost-effectiveness, including deep infection and nonunion rates of HTO and a plausible range of rehabilitation costs, acute recovery costs, and physician fees for HTO, UKA, and TKA.

\section{Probabilistic Sensitivity Analysis}

Figure 3 shows a cost-effectiveness scatter plot of 10,000 iterations of cost-effectiveness analyses. This figure demonstrates possible outcomes for costs and effectiveness for each procedure when joint uncertainty regarding multiple parameters was considered. The cost-effectiveness acceptability curve (Fig. 4) shows the frequency at which each strategy was found to be costeffective over 10,000 iterations. At the WTP threshold of $\$ 50,000$ per QALY, HTO was cost-effective in $57 \%$ of the simulations; 
TABLE III Expected Value of Partial Perfect Information*

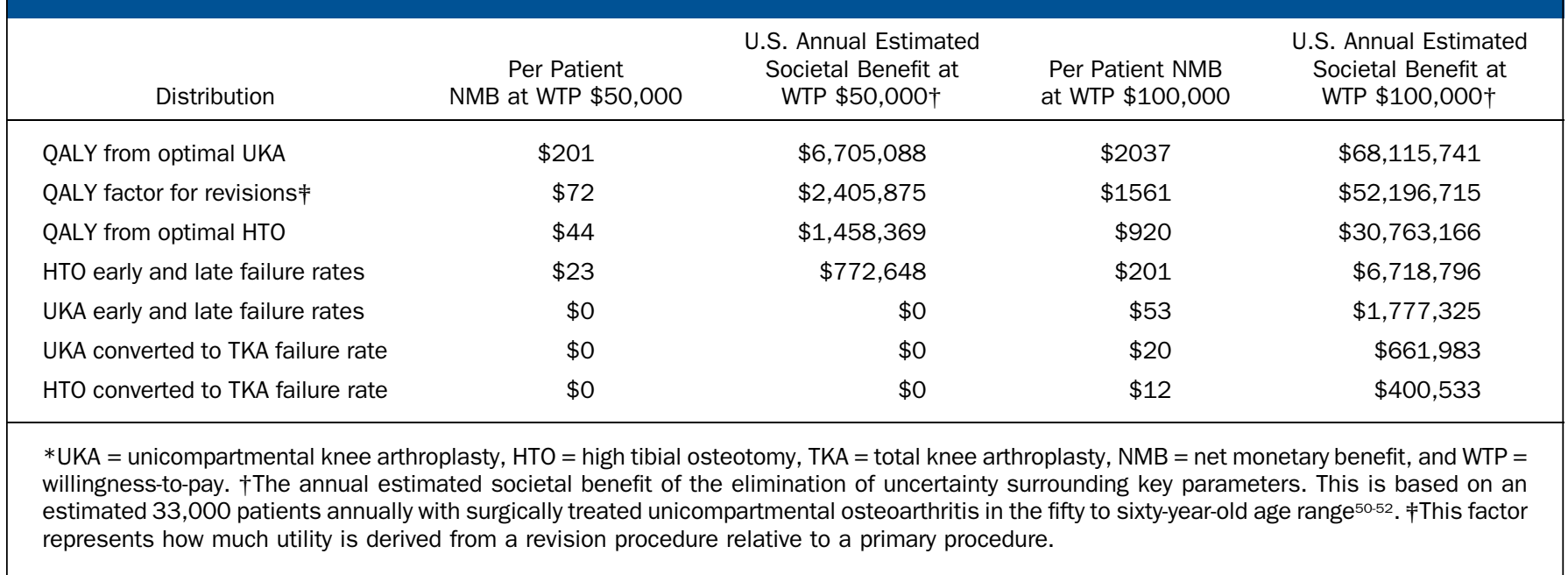

TKA, in 24\%; and UKA, in 19\%. At the WTP threshold of $\$ 100,000$ per QALY, HTO was cost-effective in $43 \%$ of the simulations; TKA, in 31\%; and UKA, in $26 \%$.

\section{EVPPI}

EVPPI analysis (Table III) indicated that the greatest benefit was derived from eliminating uncertainty surrounding the quality of life experienced following optimal UKA and HTO relative to TKA as well as the quality of life derived from UKA and HTO conversions to TKA. Less benefit was derived from further reducing uncertainty regarding failure rates of UKA and HTO to TKA.

\section{Discussion}

$\mathrm{W}$ e examined the cost-effectiveness of HTO, UKA, and TKA in younger patients with advanced medial unicompartmental knee osteoarthritis. Within WTP thresholds of $\$ 50,000$ per QALY to $\$ 150,000$ per QALY, HTO demonstrated the highest likelihood of being the most cost-effective treatment. Our results support greater utilization of HTO in younger persons with medial unicompartmental knee osteoarthritis. However, uncertainty surrounding key parameters, including quality-of-life improvements from conversion of HTO and UKA to TKA, prevents the dismissal of UKA and TKA as reasonable treatment options on costeffectiveness grounds.

HTO and UKA are often used to "buy time" for younger patients until TKA is ultimately undertaken. Our model predicts that both HTO and UKA effectively delay the need for TKA, with rates of conversion within ten years of $16 \%$ and $18 \%$, respectively, which is consistent with published data ${ }^{83}$. Furthermore, both procedures delay the need for revision TKA, which may have the poorest outcomes ${ }^{20,53}$. In contrast, our estimated lifetime TKA revision rate for primary TKA was 37\%, which is consistent with reported survivorship in younger patients ${ }^{84}$.

The clinical performance of HTO converted to TKA is not well established, with some studies suggesting worse outcomes relative to primary TKA and others suggesting similar out- comes ${ }^{4-6,28,85-90}$. Likewise, data on UKA conversions are inconsistent $^{76,91,92}$, although several authors have demonstrated that UKA converted to TKA compares unfavorably with primary TKA, with increased technical complexity ${ }^{77,78,93-95}$, poorer func$\operatorname{tion}^{6,13,75,77,78,96}$, and higher revision rates ${ }^{6,53}$. Two studies that directly compared HTO and UKA conversions to TKA found better results with HTO conversions ${ }^{6,97}$. Our study found that HTO is cost-effective even if the quality of life from a conversion to TKA is between that of primary TKA and revision TKA. However, a UKA converted to a TKA needed to approach the quality of life of primary TKA for UKA to be cost-effective.

The results of our analysis, which focused on younger patients, add to existing literature on cost-effectiveness of UKA and TKA in older patients. Soohoo et al. ${ }^{21}$ found that UKA had similar lifetime costs and effectiveness as TKA in sixty-five-year-olds, as long as UKA survival was within three to four years of TKA survival. Slover et al. ${ }^{22}$ found that UKA was cost-effective in seventy-eight-year-olds, as long as annual revision rates were $<4 \%$. Our study found that an HTO conversion rate of $<2.6 \%$ annually and a UKA conversion rate of $<2.0 \%$ annually are necessary for these procedures to be cost-effective options for younger patients.

The results of probabilistic sensitivity analysis suggested uncertainty regarding the cost-effectiveness of HTO. At the WTP threshold of $\$ 50,000$ per QALY, the probability that HTO is costeffective did not exceed 57\%. Although HTO had the highest probability of being the cost-effective strategy throughout the policy-relevant WTP range of $\$ 50,000$ per QALY to $\$ 150,000$ per QALY, the current state of the data precludes us from rejecting UKA and TKA on cost-effectiveness grounds. Although HTO leads to lower costs, surgeon experience and patient preferences are key factors that we could not model. From an implementation perspective, HTO may be more technically difficult than UKA or TKA, and its success may be driven by surgeon volume. Such factors may substantially influence outcomes.

Our study had several limitations. In the absence of data, we assumed an age-based rate of revision surgery for aseptic 
prosthetic failures. We also assumed similar age-adjusted medical complication rates for primary and revision procedures. However, sensitivity analyses demonstrated that the outcome of our study was not affected by these assumptions. Additionally, where data from multiple sources were available, we derived pooled results from existing studies weighted by study sample sizes. In recognition of inconsistent results across studies, we performed deterministic and probabilistic sensitivity analyses to examine the effects of these uncertainties on our conclusions.

As previous authors have noted ${ }^{21,98}$, a wide range of estimates for postoperative QALYs are reported throughout the literature, even for TKA. In the absence of studies designed to directly measure the utility of HTO, UKA, and TKA, as well as subsequent revisions, we used the median of reported values for the QALYs derived from TKA. We assumed the quality of life derived from HTO and UKA was similar on the basis of studies that measured relative outcomes with knee-specific outcome instruments. Furthermore, we estimated that the QALYs derived from HTO or UKA converted to TKA were midway between that of revision TKA and primary TKA on the basis of a small number of reports comparing these procedures.

Our study finds that in fifty to sixty-year-old patients with medial unicompartmental knee osteoarthritis, HTO is, from a costeffectiveness perspective, an attractive treatment option compared with UKA and TKA. Among the three strategies considered, HTO had the highest probability of being cost-effective, and UKA had the lowest likelihood of being cost-effective; this conclusion is sensitive to annual conversion rates to TKA. Our findings support greater utilization of HTO in patients of this age range with medial knee osteoarthritis, if annual conversion rates of HTO are $<2.6 \%$ and UKA conversion rates are $>2.0 \%$. However, based on uncertainty in key efficacy parameters in the current literature, no strategy could be uniformly supported or rejected on cost-effectiveness grounds. We recommend that additional research be directed at clarifying the utility derived from HTO and UKA when converted to TKA. Randomized controlled trials comparing long-term outcomes of TKA, HTO, and UKA, including index TKA revision and conversion of HTO and UKA to TKA and subsequent TKA revision, would further inform medical decision-making for younger patients with medial unicompartmental osteoarthritis.

\section{Appendix}

The methods used for deriving costs for each surgery and the distributions used for probabilistic sensitivity analysis are described below.

\section{Costs}

\section{Preoperative Costs}

Preoperative costs included the initial physician visit, preoperative imaging, and preoperative laboratory tests, and were derived from the Centers for Medicare \& Medicaid Services (CMS) 2012 Physician Fee Schedule ${ }^{112}$, Hospital Outpatient Prospective Payment System rules ${ }^{113}$, and the 2012 Clinical Laboratory Fee Schedule ${ }^{114}$.

\section{Procedure Costs}

Anesthesia professional fees were determined from the CMS Anesthesia Fee Schedule for $2012^{115}$. Surgeon fees were also de- termined from the 2012 Physician Fee Schedule. Surgery-related technical needs and acute inpatient recovery costs were determined using the appropriate DRG (diagnosis-related group).

\section{Post-Acute Recovery Costs}

Costs associated with postoperative rehabilitation-including the utilization of outpatient physical therapy, home health care, skilled nursing facilities, and inpatient rehabilitation facilities-were determined by multiplying the costs associated with each form of rehabilitation ${ }^{118}$ by the utilization rates as determined by the Healthcare Cost and Utilization Project (HCUP) ${ }^{119}$ of the U.S. Department of Health \& Human Services Agency for Healthcare Research and Quality and from the data of Lombardi et al. ${ }^{70}$. Postoperative medication expenses were determined by applying average medication prices ${ }^{116}$ to a typical postoperative medication regimen. Expenses for postoperative follow-up were determined using follow-up rates from a survey of joint replacement surgeons ${ }^{117}$ as well as physician visit and imaging expenses derived from the 2012 Physician Fee Schedule ${ }^{112}$.

\section{Cost of Complications}

The costs of major perioperative medical complications were determined by taking a weighted average of median costs from HCUP data ${ }^{119}$ multiplied by the frequency of each complication in knee arthroplasty patients as found by Mantilla et al. ${ }^{55}$. Expenses associated with conservative treatment of a suboptimal or failed prosthesis were estimated by multiplying the costs of conservative treatment of severe end-stage osteoarthritis, as determined in a
TABLE IV Distributions Used in Probabilistic Sensitivity Analysis*

Parameter Distribution
Age
Probability of early HTO implant failure
Probability of late HTO implant failure
Probability of early UKA implant failure
Probability of late UKA implant failure
Probability of early TKA implant failure
Probability of late TKA implant failure
Probability of failure of HTO converted to TKA
Probability of failure of UKA converted to TKA
Probability of revision TKA failure
QALY from optimal primary implant
QALY factor for revision TKA $†$
Uniform (50-60)
Beta $(38,1104)$
Beta $(113,4777)$
Beta $(161,5951)$
Beta $(113,4777)$
Beta $(29,4975)$
Beta $(48,3955)$
Beta $(37,2261)$
Beta $(37,2261)$
Beta $(36,972)$
Normal $(0.835,0.005)$
Uniform (0.87-0.98)

$*$ HTO $=$ high tibial osteotomy, UKA $=$ unicompartmental knee arthroplasty, TKA = total knee arthroplasty, and QALY = qualityadjusted life-year. Early failure $=$ the probability of failure of the implant within one year of the procedure, and late failure $=$ the annual probability of implant failure after one year postoperatively. †Expressed as a multiple of QALYs from an optimal primary implant. 
The Journal of Bone \& Joint Surgery $\cdot$ Jbjs.org VOlume 97-A $\cdot$ Number $10 \cdot$ May 20, 2015
Cost-Effectiveness of Surgical Treatment of Medial

Unicompartmental KneE Osteoarthritis prior study ${ }^{62}$, by $50 \%$ because this value could not otherwise be accurately determined.

\section{Distributions}

Beta distributions were applied to the probabilities of failure of HTO, UKA, and TKA both within the first postoperative year and annually thereafter. Beta distributions were also applied to the failure rates of revision implants. All beta distributions were determined by examining the number of failed events out of the number of patients in the source studies for the corresponding point estimates listed in Table IV. A normal distribution was applied to the utility derived from primary TKA according to a previously published distribution ${ }^{62}$. Quality of life resulting from a revision TKA was determined by multiplying a factor obtained from a uniform distribution of $87 \%$ to $98 \%$ by the utility of a primary TKA, which encompassed the range of values from published sources $^{21,22,25,64,67,109}$.
Joseph F. Konopka, MD, MSc

Thomas S. Thornhill, MD

Jeffrey N. Katz, MD, MSc

Elena Losina, $\mathrm{PhD}$

Orthopedic and Arthritis Center for Outcomes Research

(J.F.K., J.N.K., and E.L.),

Department of Orthopedic Surgery

(J.F.K., T.S.T., J.N.K., and E.L.),

Brigham and Women's Hospital,

75 Francis Street, BC-4016,

Boston, MA 02115.

E-mail address for E. Losina: elosina@partners.org

Andreas H. Gomoll, MD

Department of Orthopedic Surgery,

Brigham and Women's Hospital,

Harvard Medical School,

850 Boylston Street,

Chestnut Hill, MA 02467

\section{References}

1. Price $A$, Beard D, Thienpont $E$. Uncertainties surrounding the choice of surgical treatment for 'bone on bone' medial compartment osteoarthritis of the knee. Knee. 2013 Sep;20(Suppl 1):S16-20.

2. Smith JO, Wilson AJ, Thomas NP. Osteotomy around the knee: evolution, principles and results. Knee Surg Sports Traumatol Arthrosc. 2013 Jan;21(1):3-22. Epub 2012 Sep 29.

3. Spahn G, Hofmann GO, von Engelhardt LV, Li M, Neubauer H, Klinger HM. The impact of a high tibial valgus osteotomy and unicondylar medial arthroplasty on the treatment for knee osteoarthritis: a meta-analysis. Knee Surg Sports Traumatol Arthrosc. 2013 Jan;21(1):96-112. Epub 2011 Nov 11.

4. Haslam P, Armstrong M, Geutjens G, Wilton TJ. Total knee arthroplasty after failed high tibial osteotomy long-term follow-up of matched groups. J Arthroplasty. $2007 \mathrm{Feb} ; 22(2): 245-50$.

5. Nizard RSCL, Cardinne L, Bizot P, Witvoet J. Total knee replacement after failed tibial osteotomy: results of a matched-pair study. J Arthroplasty. 1998 Dec;13 (8):847-53.

6. Pearse AJ, Hooper GJ, Rothwell AG, Frampton C. Osteotomy and unicompartmental knee arthroplasty converted to total knee arthroplasty: data from the New Zealand Joint Registry. J Arthroplasty. 2012 Dec;27(10):1827-31. Epub 2012 Oct 11. 7. Kozinn SC, Scott R. Unicondylar knee arthroplasty. J Bone Joint Surg Am. 1989 Jan;71(1):145-50.

8. Pandit H, Jenkins C, Gill HS, Smith G, Price AJ, Dodd CA, Murray DW. Unnecessary contraindications for mobile-bearing unicompartmental knee replacement. J Bone Joint Surg Br. 2011 May;93(5):622-8.

9. Borus $\mathrm{T}$, Thornhill T. Unicompartmental knee arthroplasty. J Am Acad Orthop Surg. 2008 Jan;16(1):9-18.

10. W-Dahl A, Robertsson O, Lidgren L. Surgery for knee osteoarthritis in younger patients. Acta Orthop. $2010 \mathrm{Apr} ; 81(2): 161-4$.

11. Argenson JN, Parratte S, Bertani A, Flecher X, Aubaniac JM. Long-term results with a lateral unicondylar replacement. Clin Orthop Relat Res. 2008 Nov;466 (11):2686-93. Epub 2008 Jun 24.

12. Biswas D, Van Thiel GS, Wetters NG, Pack BJ, Berger RA, Della Valle CJ. Medial unicompartmental knee arthroplasty in patients less than 55 years old: minimum of two years of follow-up. J Arthroplasty. 2014 Jan;29(1):101-5. Epub 2013 May 31.

13. Chou DT, Swamy GN, Lewis JR, Badhe NP. Revision of failed unicompartmental knee replacement to total knee replacement. Knee. 2012 Aug;19(4):356-9. Epub 2011 Jun 1.

14. Clement ND, Duckworth AD, MacKenzie SP, Nie YX, Tiemessen CH. Mediumterm results of Oxford phase-3 medial unicompartmental knee arthroplasty. J Orthop Surg (Hong Kong). 2012 Aug;20(2):157-61.

15. Gioe TJ, Novak C, Sinner P, Ma W, Mehle S. Knee arthroplasty in the young patient: survival in a community registry. Clin Orthop Relat Res. 2007 Nov;464:83-7. 16. Harrysson OL, Robertsson 0 , Nayfeh JF. Higher cumulative revision rate of knee arthroplasties in younger patients with osteoarthritis. Clin Orthop Relat Res. 2004 Apr;421:162-8.

17. Newman J, Pydisetty RV, Ackroyd C. Unicompartmental or total knee replacement: the 15-year results of a prospective randomised controlled trial. J Bone Joint Surg Br. 2009 Jan;91(1):52-7.
18. Parratte S, Argenson JN, Pearce O, Pauly V, Auquier P, Aubaniac JM. Medial unicompartmental knee replacement in the under-50s. J Bone Joint Surg Br. 2009 Mar;91(3):351-6.

19. Keeney JAES, Eunice S, Pashos G, Wright RW, Clohisy JC. What is the evidence for total knee arthroplasty in young patients?: a systematic review of the literature. Clin Orthop Relat Res. 2011 Feb;469(2):574-83. Epub 2010 Sep 3.

20. Dudley TE, Gioe TJ, Sinner P, Mehle S. Registry outcomes of unicompartmental knee arthroplasty revisions. Clin Orthop Relat Res. 2008 Jul;466(7):1666-70. Epub 2008 May 9.

21. Soohoo NF, Sharifi H, Kominski G, Lieberman JR. Cost-effectiveness analysis of unicompartmental knee arthroplasty as an alternative to total knee arthroplasty for unicompartmental osteoarthritis. J Bone Joint Surg Am. 2006 Sep;88(9):1975-82.

22. Slover J, Espehaug B, Havelin LI, Engesaeter LB, Furnes O, Tomek I, Tosteson A. Cost-effectiveness of unicompartmental and total knee arthroplasty in elderly lowdemand patients. A Markov decision analysis. J Bone Joint Surg Am. 2006 Nov;88 (11):2348-55.

23. Koskinen E, Eskelinen A, Paavolainen $P$, Pulkkinen P, Remes V. Comparison of survival and cost-effectiveness between unicondylar arthroplasty and total knee arthroplasty in patients with primary osteoarthritis: a follow-up study of 50,493 knee replacements from the Finnish Arthroplasty Register. Acta Orthop. 2008 Aug;79 (4):499-507.

24. Xie F, Lo NN, Tarride JE, O'Reilly D, Goeree R, Lee HP. Total or partial knee replacement? Cost-utility analysis in patients with knee osteoarthritis based on a 2-year observational study. Eur J Health Econ. 2010 Feb;11(1):27-34. Epub 2009 May 10.

25. Brown CA, Watters TS, Mather RC, Orlando LA, Bolognesi MP, Moorman CT. Cost-effectiveness analysis of unicompartmental knee arthroplasty and high tibial osteotomy for treatment of medial compartmental osteoarthritis. Duke Orthopedic Journal. 2011 Jun;1(1):23-37.

26. W-Dahl A, Robertsson O, Lidgren L, Miller L, Davidson D, Graves S. Unicompartmental knee arthroplasty in patients aged less than 65. Acta Orthop. 2010 Feb;81(1):90-4.

27. Amin AK, Patton JT, Cook RE, Gaston M, Brenkel IJ. Unicompartmental or total knee arthroplasty?: results from a matched study. Clin Orthop Relat Res. 2006 Oct; 451:101-6.

28. Argenson JN, Blanc G, Aubaniac JM, Parratte S. Modern unicompartmental knee arthroplasty with cement: a concise follow-up, at a mean of twenty years, of a previous report. J Bone Joint Surg Am. 2013 May 15;95(10):905-9.

29. Curtin B, Malkani A, Lau E, Kurtz S, Ong K. Revision after total knee arthroplasty and unicompartmental knee arthroplasty in the Medicare population. J Arthroplasty. 2012 Sep;27(8):1480-6. Epub 2012 Apr 3.

30. Emerson RH Jr, Higgins LL. Unicompartmental knee arthroplasty with the Oxford prosthesis in patients with medial compartment arthritis. J Bone Joint Surg Am. 2008 Jan;90(1):118-22.

31. Heyse TJ, Efe T, Rumpf S, Schofer MD, Fuchs-Winkelmann S, Schmitt J, Hauk C. Minimally invasive versus conventional unicompartmental knee arthroplasty. Arch Orthop Trauma Surg. 2011 Sep;131(9):1287-90. Epub 2011 Feb 18.

32. Koskinen E, Paavolainen P, Eskelinen A, Harilainen A, Sandelin J, Ylinen P, Tallroth K, Remes V. Medial unicompartmental knee arthroplasty with Miller-Galante II 
The Journal of Bone \& Joint Surgery - jbjs.org Volume 97-A - Number 10 - MAY 20, 2015
Cost-Effectiveness of Surgical Treatment of Medial

Unicompartmental KneE OSteoarthritis prosthesis: mid-term clinical and radiographic results. Arch Orthop Trauma Surg. 2009 May;129(5):617-24. Epub 2008 Jun 17.

33. Liebs TR, Herzberg W. Better quality of life after medial versus lateral unicondylar knee arthroplasty. Clin Orthop Relat Res. 2013 Aug;471(8):2629-40. Epub 2013 Apr 9. 34. Lyons MC, MacDonald SJ, Somerville LE, Naudie DD, McCalden RW. Unicompartmental versus total knee arthroplasty database analysis: is there a winner? Clin Orthop Relat Res. 2012 Jan;470(1):84-90.

35. O’Donnell T, Neil MJ. The Repicci IIß unicondylar knee arthroplasty: 9-year survivorship and function. Clin Orthop Relat Res. 2010 Nov;468(11):3094-102. Epub 2010 Aug 13.

36. Pandit $\mathrm{H}$, Jenkins $\mathrm{C}$, Barker $\mathrm{K}$, Dodd CA, Murray DW. The Oxford medial unicompartmental knee replacement using a minimally-invasive approach. J Bone Joint Surg Br. 2006 Jan;88(1):54-60.

37. Price AJ, Svard U. A second decade lifetable survival analysis of the Oxford unicompartmental knee arthroplasty. Clin Orthop Relat Res. 2011 Jan;469(1): 174-9.

38. Price AJ, Waite JC, Svard U. Long-term clinical results of the medial Oxford unicompartmental knee arthroplasty. Clin Orthop Relat Res. 2005 Jun;435:171-80. 39. Sibanda N, Copley LP, Lewsey JD, Borroff M, Gregg P, MacGregor AJ, Pickford M, Porter M, Tucker K, van der Meulen JH; Steering Committee of the National Joint Registry (NJR) for England and Wales. Revision rates after primary hip and knee replacement in England between 2003 and 2006. PLoS Med. 2008 Sep 30;5(9): e179. Epub 2008 Sep 2.

40. Fu D, Li G, Chen K, Zhao Y, Hua Y, Cai Z. Comparison of high tibial osteotomy and unicompartmental knee arthroplasty in the treatment of unicompartmental osteoarthritis: a meta-analysis. J Arthroplasty. 2013 May;28(5):759-65. Epub 2013 Mar 15.

41. TreeAge Pro Suite 2013, R1.0. TreeAge Software. Williamstown, MA. https:// www.treeage.com/news/treeage-pro-2013-r1/. Accessed 2015 Feb 23.

42. National Institute for Health and Care Excellence. 2014. http://www.nice.org. uk. Accessed 2015 Feb 4.

43. Weinstein MC, Siegel JE, Gold MR, Kamlet MS, Russell LB. Recommendations of the Panel on Cost-effectiveness in Health and Medicine. JAMA. 1996 Oct 16;276 (15):1253-8.

44. Bambha K, Kim WR. Cost-effectiveness analysis and incremental costeffectiveness ratios: uses and pitfalls. Eur J Gastroenterol Hepatol. 2004 Jun;16 (6):519-26.

45. King JT Jr, Tsevat J, Lave JR, Roberts MS. Willingness to pay for a qualityadjusted life year: implications for societal health care resource allocation. Med Decis Making. 2005 Nov-Dec;25(6):667-77.

46. Neumann PJ, Cohen JT, Weinstein MC. Updating cost-effectiveness-the curious resilience of the \$50,000-per-QALY threshold. N Engl J Med. 2014 Aug 28;371(9):796-7.

47. Siegel JE, Weinstein MC, Russell LB, Gold MR; Panel on Cost-Effectiveness in Health and Medicine. Recommendations for reporting cost-effectiveness analyses. JAMA. 1996 Oct 23-30;276(16):1339-41.

48. Griffin S, Claxton $\mathrm{K}$. Interpreting the expected value of perfect information about parameters. Presented as a poster exhibit at the 29th Annual Meeting of the Society for Medical Decision Making; 2007 Oct 20-24; Pittsburgh, PA. Poster no. 4-31.

49. Centers for Disease Control and Prevention. Life Tables. http://www.cdc.gov/ nchs/products/life_tables.htm. Accessed $2015 \mathrm{Feb} 23$.

50. Riddle DL, Jiranek WA, McGlynn FJ. Yearly incidence of unicompartmental knee arthroplasty in the United States. J Arthroplasty. 2008 Apr;23(3):408-12. Epub 2007 Nov 26.

51. Weinstein AM, Rome BN, Reichmann WM, Collins JE, Burbine SA, Thornhill TS, Wright J, Katz JN, Losina E. Estimating the burden of total knee replacement in the United States. J Bone Joint Surg Am. 2013 Mar 6;95(5):385-92.

52. Woolson ST, Shu B, Giori NJ. Incidence of radiographic unicompartmental arthritis in patients undergoing knee arthroplasty. Orthopedics. 2010 Nov;33

(11):798. Epub 2010 Nov 2.

53. Hang JR, Stanford TE, Graves SE, Davidson DC, de Steiger RN, Miller LN. Outcome of revision of unicompartmental knee replacement. Acta Orthop. 2010 Feb;81 (1):95-8.

54. Masters JP, Smith NA, Foguet $P$, Reed $M$, Parsons $H$, Sprowson AP. A systematic review of the evidence for single stage and two stage revision of infected knee replacement. BMC Musculoskelet Disord. 2013;14:222. Epub 2013 Jul 29. 55. Mantilla CB, Horlocker $T$, Schroeder DR, Berry DJ, Brown DL. Risk factors for clinically relevant pulmonary embolism and deep venous thrombosis in patients undergoing primary hip or knee arthroplasty. Anesthesiology. 2003 Sep;99(3): 552-60; discussion 5A.

56. Duchman KR, Gao Y, Pugely AJ, Martin CT, Callaghan JJ. Differences in shortterm complications between unicompartmental and total knee arthroplasty: a propensity score matched analysis. J Bone Joint Surg Am. 2014 Aug 20;96(16): 1387-94.

57. Winder RP, Severson EP, Trousdale RT, Pagnano MW, Wood-Wentz CM, Sierra RJ. No difference in 90-day complications between bilateral unicompartmental and total knee arthroplasty. Am J Orthop (Belle Mead NJ). 2014 Feb;43(2):E30-3.
58. Anagnostakos $K$, Mosser $P$, Kohn D. Infections after high tibial osteotomy. Knee Surg Sports Traumatol Arthrosc. 2013 Jan;21(1):161-9. Epub 2012 Jun 23. 59. Vena G, D'Adamio S, Amendola A. Complications of osteotomies about the knee. Sports Med Arthrosc. 2013 Jun;21(2):113-20.

60. Labek G, Thaler M, Janda W, Agreiter M, Stöckl B. Revision rates after total joint replacement: cumulative results from worldwide joint register datasets. J Bone Joint Surg Br. 2011 Mar;93(3):293-7.

61. Courville XF, Tomek IM, Kirkland KB, Birhle M, Kantor SR, Finlayson SR. Costeffectiveness of preoperative nasal mupirocin treatment in preventing surgical site infection in patients undergoing total hip and knee arthroplasty: a cost-effectiveness analysis. Infect Control Hosp Epidemiol. 2012 Feb;33(2):152-9.

62. Losina E, Walensky RP, Kessler CL, Emrani PS, Reichmann WM, Wright EA, Holt HL, Solomon DH, Yelin E, Paltiel AD, Katz JN. Cost-effectiveness of total knee arthroplasty in the United States: patient risk and hospital volume. Arch Intern Med. 2009 Jun 22;169(12):1113-21; discussion 1121-2.

63. McDonald H, Diamantopoulos A, Wells P, Lees M, Folkerts K, Forster F, Ananthapavan J. Cost-effectiveness of rivaroxaban in the prevention of venous thromboembolism: a Canadian analysis using the Ontario Ministry of Health Perspective. J Med Econ. 2012;15(5):817-28. Epub 2012 Apr 24.

64. Novak EJ, Silverstein MD, Bozic KJ. The cost-effectiveness of computerassisted navigation in total knee arthroplasty. J Bone Joint Surg Am. 2007 Nov;89 (11):2389-97.

65. Räsänen $P$, Paavolainen $P$, Sintonen $H$, Koivisto $A M$, Blom $M$, Ryynänen $O P$, Roine RP. Effectiveness of hip or knee replacement surgery in terms of qualityadjusted life years and costs. Acta Orthop. 2007 Feb;78(1):108-15.

66. Ryttberg L, Diamantopoulos A, Forster F, Lees M, Fraschke A, Björholt I. Costeffectiveness of rivaroxaban versus heparins for prevention of venous thromboembolism after total hip or knee surgery in Sweden. Expert Rev Pharmacoecon Outcomes Res. 2011 Oct:11(5):601-15.

67. Tengs TO, Wallace A. One thousand health-related quality-of-life estimates. Med Care. 2000 Jun;38(6):583-637.

68. Tso P, Walker K, Mahomed N, Coyte PC, Rampersaud YR. Comparison of lifetime incremental cost:utility ratios of surgery relative to failed medical management for the treatment of hip, knee and spine osteoarthritis modelled using 2-year postsurgical values. Can J Surg. 2012 Jun;55(3):181-90.

69. Foote JA, Smith HK, Jonas SC, Greenwood R, Weale AE. Return to work following knee arthroplasty. Knee. 2010 Jan;17(1):19-22. Epub 2009 Jul 24.

70. Lombardi AV Jr, Berend KR, Walter CA, Aziz-Jacobo J, Cheney NA. Is recovery faster for mobile-bearing unicompartmental than total knee arthroplasty? Clin Orthop Relat Res. 2009 Jun;467(6):1450-7. Epub 2009 Feb 19.

71. Sun PF, Jia YH. Mobile bearing UKA compared to fixed bearing TKA: a randomized prospective study. Knee. 2012 Mar:19(2):103-6. Epub 2011 Feb 22.

72. Willis-Owen CA, Brust K, Alsop H, Miraldo M, Cobb JP. Unicondylar knee arthroplasty in the UK National Health Service: an analysis of candidacy, outcome and cost efficacy. Knee. 2009 Dec;16(6):473-8. Epub 2009 May 22.

73. Wylde V, Blom A, Dieppe P, Hewlett S, Learmonth I. Return to sport after joint replacement. J Bone Joint Surg Br. 2008 Jul;90(7):920-3.

74. Dakin H, Gray A, Fitzpatrick R, Maclennan G, Murray D; KAT Trial Group. Rationing of total knee replacement: a cost-effectiveness analysis on a large trial data set. BMJ Open. 2012;2(1):e000332. Epub 2012 Jan 30.

75. Järvenpää J, Kettunen J, Miettinen $\mathrm{H}$, Kröger $\mathrm{H}$. The clinical outcome of revision knee replacement after unicompartmental knee arthroplasty versus primary total knee arthroplasty: 8-17 years follow-up study of 49 patients. Int Orthop. 2010 Jun;34 (5):649-53. Epub 2009 May 27.

76. O'Donnell TM, Abouazza 0 , Neil MJ. Revision of minimal resection resurfacing unicondylar knee arthroplasty to total knee arthroplasty: results compared with primary total knee arthroplasty. J Arthroplasty. 2013 Jan;28(1):33-9. Epub 2012 Jul 17. 77. Rancourt MF, Kemp KA, Plamondon SM, Kim PR, Dervin GF. Unicompartmental knee arthroplasties revised to total knee arthroplasties compared with primary total knee arthroplasties. J Arthroplasty. 2012 Sep;27(8)(Suppl):106-10. Epub 2012 Apr 13.

78. Sarraf KM, Konan S, Pastides PS, Haddad FS, Oussedik S. Bone loss during revision of unicompartmental to total knee arthroplasty: an analysis of implanted polyethylene thickness from the National Joint Registry data. J Arthroplasty. 2013 Oct;28(9):1571-4. Epub 2013 Mar 26.

79. Slover JD, Tosteson AN, Bozic KJ, Rubash HE, Malchau H. Impact of hospital volume on the economic value of computer navigation for total knee replacement. J Bone Joint Surg Am. 2008 Jul;90(7):1492-500.

80. Bureau of Labor Statistics. United States Department of Labor. http://www.bls. gov/data/. Accessed 2015 Feb 25.

81. Briggs AH, Gagnon YM, Levy AR. Probabilistic costeffectiveness modeling: overview of methods and challenges with an interactive illustration. Paper presented at the 7th Annual International Meeting of the International Society for Pharmacoeconomics and Outcomes Research; 2002 May 19-22; Arlington, VA. Paper no. WW3.

82. O'Brien BJ, Briggs AH. Analysis of uncertainty in health care cost-effectiveness studies: an introduction to statistical issues and methods. Stat Methods Med Res. 2002 Dec;11(6):455-68. 
The Journal of Bone \& Joint Surgery $\cdot$ Jbjs.org Volume 97-A $\cdot$ Number $10 \cdot$ May 20, 2015
Cost-Effectiveness of Surgical Treatment of Medial

Unicompartmental KneE Osteoarthritis
83. Gomoll $\mathrm{AH}$. High tibial osteotomy for the treatment of unicompartmental knee osteoarthritis: a review of the literature, indications, and technique. Phys Sportsmed. 2011 Sep;39(3):45-54.

84. Long WJ, Bryce CD, Hollenbeak CS, Benner RW, Scott WN. Total knee replacement in young, active patients: long-term follow-up and functional outcome: a concise follow-up of a previous report. J Bone Joint Surg Am. 2014 Sep 17;96(18): e159.

85. Haddad FS, Bentley G. Total knee arthroplasty after high tibial osteotomy: a medium-term review. J Arthroplasty. 2000 Aug;15(5):597-603.

86. Kazakos KJ, Chatzipapas C, Verettas D, Galanis V, Xarchas KC, Psillakis I. Midterm results of total knee arthroplasty after high tibial osteotomy. Arch Orthop Trauma Surg. 2008 Feb;128(2):167-73. Epub 2007 Nov 16.

87. Meding JB, Wing JT, Ritter MA. Does high tibial osteotomy affect the success or survival of a total knee replacement? Clin Orthop Relat Res. 2011 Jul;469(7):19914. Epub 2011 Mar 18.

88. Meding JBKE, Keating EM, Ritter MA, Faris PM. Total knee arthroplasty after high tibial osteotomy. A comparison study in patients who had bilateral total knee replacement. J Bone Joint Surg Am. 2000 Sep;82(9):1252-9.

89. Niinimäki T, Eskelinen A, Ohtonen $P$, Puhto AP, Mann BS, Leppilahti J. Total knee arthroplasty after high tibial osteotomy: a registry-based case-control study of 1,036 knees. Arch Orthop Trauma Surg. 2014 Jan;134(1):73-7. Epub 2013 Nov 26. 90. van Raaij TM, Bakker W, Reijman M, Verhaar JA. The effect of high tibial osteotomy on the results of total knee arthroplasty: a matched case control study. BMC Musculoskelet Disord. 2007;8:74. Epub 2007 Aug 3.

91. Springer BD, Scott RD, Thornhill TS. Conversion of failed unicompartmental knee arthroplasty to TKA. Clin Orthop Relat Res. 2006 May;446:214-20.

92. Centers for Medicare \& Medicaid Services. Diagnosis Related Group List, FY 2011. http://www.cms.gov/Medicare/Medicare-Fee-for-Service-Payment/ AcutelnpatientPPS/Acute-Inpatient-Files-for-Download-Items/CMS1255464.html. Accessed 2015 Feb 23

93. Saldanha KA, Keys GW, Svard UC, White SH, Rao C. Revision of Oxford medial unicompartmental knee arthroplasty to total knee arthroplasty - results of a multicentre study. Knee. 2007 Aug;14(4):275-9. Epub 2007 May 23.

94. Siddiqui NA, Ahmad ZM. Revision of unicondylar to total knee arthroplasty: a systematic review. Open Orthop J. 2012;6:268-75. Epub 2012 Jul 27.

95. Wynn Jones H, Chan W, Harrison T, Smith TO, Masonda P, Walton NP. Revision of medial Oxford unicompartmental knee replacement to a total knee replacement: similar to a primary? Knee. 2012 Aug;19(4):339-43. Epub 2011 Apr 29.

96. Pearse AJ, Hooper GJ, Rothwell A, Frampton C. Survival and functional outcome after revision of a unicompartmental to a total knee replacement: the New Zealand National Joint Registry. J Bone Joint Surg Br. 2010 Apr;92(4):508-12.

97. Gill T, Schemitsch EH, Brick GW, Thornhill TS. Revision total knee arthroplasty after failed unicompartmental knee arthroplasty or high tibial osteotomy. Clin Orthop Relat Res. 1995 Dec;321:10-8.

98. Ethgen $O$, Bruyère $O$, Richy $F$, Dardennes $C$, Reginster JY. Health-related quality of life in total hip and total knee arthroplasty. A qualitative and systematic review of the literature. J Bone Joint Surg Am. 2004 May;86(5):963-74.

99. Asik M, Sen C, Kilic B, Goksan SB, Ciftci F, Taser OF. High tibial osteotomy with Puddu plate for the treatment of varus gonarthrosis. Knee Surg Sports Traumatol Arthrosc. 2006 Oct;14(10):948-54. Epub 2006 Apr 11.

100. Billings A, Scott DF, Camargo MP, Hofmann AA. High tibial osteotomy with a calibrated osteotomy guide, rigid internal fixation, and early motion. Long-term follow-up. J Bone Joint Surg Am. 2000 Jan;82(1):70-9.

101. Chae DJ, Shetty GM, Wang KH, Montalban AS Jr, Kim JI, Nha KW. Early complications of medial opening wedge high tibial osteotomy using autologous tricortical iliac bone graft and T-plate fixation. Knee. 2011 Aug;18(4):278-84. Epub 2010 Aug 30.
102. Efe T, Ahmed G, Heyse TJ, Boudriot U, Timmesfeld N, Fuchs-Winkelmann S, Ishaque B, Lakemeier S, Schofer MD. Closing-wedge high tibial osteotomy: survival and risk factor analysis at long-term follow up. BMC Musculoskelet Disord. 2011;12:46. Epub 2011 Feb 14.

103. El-Assal MA, Khalifa YE, Abdel-Hamid MM, Said HG, Bakr HM. Opening-wedge high tibial osteotomy without bone graft. Knee Surg Sports Traumatol Arthrosc. 2010 Jul;18(7):961-6. Epub 2010 Mar 27.

104. Hoell S, Suttmoeller J, Stoll V, Fuchs S, Gosheger G. The high tibial osteotomy, open versus closed wedge, a comparison of methods in 108 patients. Arch Orthop Trauma Surg. 2005 Nov;125(9):638-43.

105. Song EK, Seon JK, Park SJ, Jeong MS. The complications of high tibial osteotomy: closing-versus opening-wedge methods. J Bone Joint Surg Br. 2010 Sep;92 (9):1245-52.

106. Staubli AE, De Simoni $C$, Babst R, Lobenhoffer P. TomoFix: a new LCP-concept for open wedge osteotomy of the medial proximal tibia-early results in 92 cases. Injury. 2003 Nov;34(Suppl 2):B55-62.

107. Johnson $S$, Jones $P$, Newman JH. The survivorship and results of total knee replacements converted from unicompartmental knee replacements. Knee. 2007 Mar;14(2):154-7. Epub 2007 Feb 1.

108. Yim JH, Song EK, Seo HY, Kim MS, Seon JK. Comparison of high tibial osteotomy and unicompartmental knee arthroplasty at a minimum follow-up of 3 years. J Arthroplasty. 2013 Feb;28(2):243-7. Epub 2012 Jul 31.

109. Gerlier L, Lamotte M, Wille M, Kreuz PC, Vanlauwe J, Dubois D, Meurgey FM. The cost utility of autologous chondrocytes implantation using ChondroCelect ${ }^{\circledR}$ in symptomatic knee cartilage lesions in Belgium. Pharmacoeconomics. 2010;28 (12):1129-46.

110. Barrack RL, Engh G, Rorabeck C, Sawhney J, Woolfrey M. Patient satisfaction and outcome after septic versus aseptic revision total knee arthroplasty. J Arthroplasty. 2000 Dec;15(8):990-3.

111. Amendola A, Rorabeck $\mathrm{CH}$, Bourne RB, Apyan PM. Total knee arthroplasty following high tibial osteotomy for osteoarthritis. J Arthroplasty. 1989;4(Suppl): S11-7.

112. Centers for Medicare \& Medicaid Services. Physician Fee Schedule 2012. http://www.cms.gov/Medicare/Medicare-Fee-for-Service-Payment/PhysicianFeeSched/ PFS-Federal-Regulation-Notices-Items/CMS1253669.html. Accessed 2015 Feb 23.

113. Centers for Medicare \& Medicaid Services. Hospital Outpatient Prospective Payment System 2012. http://www.cms.gov/Medicare/Medicare-Fee-for-ServicePayment/HospitalOutpatientPPS/Hospital-Outpatient-Regulations-and-NoticesItems/CMS1253621.html. Accessed 2015 Feb 23.

114. Centers for Medicare \& Medicaid Services. Clinical Laboratory Fee Schedule 2012. http://www.cms.gov/Medicare/Medicare-Fee-for-Service-Payment/ ClinicalLabFeeSched/index.html. Accessed 2015 Feb 23.

115. Centers for Medicare \& Medicaid Services. 2012 Anesthesia Base Units by CPT Code 2012. http://www.cms.gov/Center/Provider-Type/AnesthesiologistsCenter.html. Accessed 2015 Feb 23.

116. Physicians Desk Reference. Red book: pharmacy's fundamental reference. Montvale, NJ: PDR Network; 2010.

117. Teeny SM, York SC, Mesko JW, Rea RE. Long-term follow-up care recommendations after total hip and knee arthroplasty: results of the American Association of Hip and Knee Surgeons' member survey. J Arthroplasty. 2003 Dec;18(8):954-62.

118. Buntin MB, Deb P, Escarce J, Hoverman C, Paddock S, Sood N. Comparison of Medicare spending and outcomes for beneficiaries with lower extremity joint replacements. Medpac report WR-271. Santa Monica, CA: RAND; 2005.

119. U.S. Department of Health and Human Services. Agency for Healthcare Research and Quality. Healthcare Cost and Utilization Project (HCUP). http://hcupnet. ahrq.gov/. Accessed 2015 Feb 4. 